\title{
Ruminal disappearance of PAHs in contaminated grass using the nylon bag technique
}

\author{
Adrián CosterA ${ }^{1 *}$, Guido RYCHEN $^{2}$, Cyril FEIDT $^{2}$, Claire SoligoT $^{2}$, Stefan JuRJANZ $^{2}$ \\ ${ }^{1}$ ISTOM, 32 boulevard du Port, 95094 Cergy-Pontoise, France \\ ${ }^{2}$ UR AFPA, Nancy-Université, INRA, 2 avenue de la Forêt de Haye BP 172, 54505 Vandœuvre-lès-Nancy Cedex, France
}

(Accepted 26 February 2010)

\begin{abstract}
Airborne polycyclic aromatic hydrocarbons (PAHs) are deposited on agricultural grasses. In turn, PAHs enter the food chain through animals eating grasses. However, the risk of food contamination, e.g. of milk, is unknown because mechanisms ruling the fate of PAHs during digestion by cows are not understood, especially in the rumen. Here, we studied the disappearance rate of phenanthrene, pyrene and benzo[a]pyrene, $n$-alkanes, and dry matter from contaminated grass samples in the rumen, the first compartment of the ruminant digestive tract. Three cows fitted with a rumen cannula were used for this study and the grass samples were incubated in sacco for $1,3,6,12,24$ and $48 \mathrm{~h}$. The results show that the disappearance rate of PAHs was fast and higher than that of $n$-alkanes. On average, $83 \%$ of PAHs disappeared after $1 \mathrm{~h}$ of incubation. Phenanthrene showed a disappearance rate higher than $90 \%$. The findings suggest a fast desorption of PAHs from the surface of the grass leaves. The digestive hydrolysis of the grass is not required to release PAHs, contrary to other fractions. As a consequence, the bioavailability of PAHs is not limited by the grass.
\end{abstract}

PAHs / in sacco / grass / $n$-alkanes / rumen

\section{INTRODUCTION}

Polycyclic Aromatic Hydrocarbons (PAHs) are considered as involuntary by-products of incomplete burning of organic matter. After atmospheric emissions, PAHs may be deposited on grasslands and consequently ingested by ruminants (Simonich and Hites, 1994; Tankari Dan-Badjo et al., 2007). The literature shows that PAHs are transferred from feed to milk (West and Horton, 1976; Grova et al., 2000, 2002). This transfer depends on the deposit method on plants, on the physicochemical properties of the compounds and on the aptitude of PAHs to be extracted from the feed matrices. Once ingested by ruminants, PAH behaviour will depend firstly on their solubilisation, which is related to the lipophilicity of each compound. Grova et al. (2005) have shown that PAHs are extensively metabolised in ruminants. Ounnas et al. (2009) concluded that apparent absorption of PAHs after oral intake is far from being negligible. Indeed, the absorption rates of parent compounds and their metabolites, which correspond at least to the urine and milk excretion rates, have been found to go above $30 \%$. In order to characterise PAH bioavailability better, it is necessary to assess the PAH release from grass in

*Corresponding author: a.costera@ istom.net the digestive tract of ruminants. The PAH localisation on the leaves needs to be specified first. According to the generic representation of the cuticle (Kunst and Samuels, 2003), the intracuticular wax is defined as an amorphous mixture of lipids soaked in cutin which binds the cuticle with the matrix of the cellular wall. The epicuticular wax refers to the lipids of the surface which form crystalloids or a smooth external layer with the cuticle. The adsorption of PAHs to these plant cuticular waxes has already been reported (Bakker et al., 2001; Wang et al., 2008). Bakker et al. (2001) even concluded that the molecular low-weight PAHs are especially present in cuticular wax and inside the leaves. Indeed, the PAHs with high molecular weight remain more or less on the surface of the leaves (epicuticular wax). A recent study showed that the concentration of PAHs in the cuticle was one to two orders of magnitude higher than that of inner tissues (Wang et al., 2008). In the case of other lipophilic compounds such as polychlorobiphenyls, it was estimated that cutin provides approximately $70-90 \%$ of the cuticle sorption capacity (Thomas et al., 1998). $\mathrm{N}$-alkanes $\left(\mathrm{C}_{23}-\mathrm{C}_{36}\right)$ are the main aliphatic constituents in the cuticular waxes of graminae (Dove and Mayes, 1991; Maffei, 1996; Ferreira et al., 2007). Indeed, hentriacontane $\left(\mathrm{C}_{31}\right)$, tritriacontane $\left(\mathrm{C}_{33}\right)$ and nonacosane $\left(\mathrm{C}_{29}\right)$ are the most 
abundant $n$-alkanes in graminae (Mayes et al., 1986; Maffei, 1996; Cortes et al., 2005). Thus, the presence of $n$-alkanes would contribute to the retention of PAHs on leaves of exposed plants.

It is known that the ruminal microflora takes a central place in the degradation of feed and vegetable fibres, and its efficiency in degradation of starch, cellulose, hemicellulose and pectin is well established (Van Soest, 1982). Contrarily, its effect on the release of $n$-alkanes as a marker of cuticular waxes and organic pollutants in the rumen, and especially of PAHs, needs to be better described. Indeed, actions of the ruminal bacteria on the link between pollutants and their matrix as well as the effect of mechanical forces of the rumen on the link between PAHs and the cuticle of leaves are still unknown. A correct evaluation of availability and metabolisation of PAHs in exposed ruminants implies knowing to what extent these contaminants are released from grass in the main digestive compartment during the ruminal fermentation process. Thus, the in sacco approach (Michalet-Doreau et al., 1987), generally used to study the disappearance kinetics of feed constituents, appears of great interest to assess the dynamics of disappearance of cuticular $n$-alkanes and grass-bound PAHs. Indeed, this technique involves using samples in nylon bags exposed to the microbial fermentation activity in the rumen. So, the obtained disappearance kinetics allow knowing the extent and speed of release of the different feed fractions in situ and therefore their availability for digestion and/or absorption. This approach, used for nutritional purposes, would also allow one to characterise the release of PAHs from the grass surface, i.e. cuticular waxes, and to see to what extent these compounds would be available for further degradation in the digestive compartments.

Thus, the objective of this study was to compare the dynamics of ruminal disappearance of different grass-bound PAHs with the disappearance of cuticular $n$-alkanes and dry matter (DM) of the same grass.

\section{MATERIAL AND METHODS}

\subsection{Grass used}

The grass used in this study was contaminated by pulverisation of phenanthrene (Phe), pyrene (Pyr) and benzo[a]pyrene (BaP) (Sigma Aldrich and Fluka, Steinheim, Germany) on a ten-square-metre meadow's grass area in the absence of rain and wind. This contamination was carried out in order to achieve the minimal concentration in grass DM to be detected by liquid chromatography (at least $10 \mu \mathrm{g} / \mathrm{g}$ DM). This level of contamination appeared necessary to ensure the good quality of the experimental design, allowing a precise determination of the disappearance kinetics in the rumen.

The treated surface was harvested (yield about $2.4 \mathrm{t} \mathrm{DM} / \mathrm{ha}$ ) the day after pulverisation in order to allow binding of PAHs on the surface of leaves. Then, the grass was dried in a climate chamber at $30{ }^{\circ} \mathrm{C}$ for 5 days to minimise volatilisation of PAHs. Then, the dried grass was manually cut to a particle size of approximately $2 \mathrm{~cm}$. Approximately $4 \mathrm{~g}$ DM of



Figure 1. $N$-alkane profiles of the graminae species used. Source: Maffei (1996) for F. arundinacea, D. glomerata and A. elatius. Ferreira et al. (2007) for L. perenne.

the PAH-contaminated grass were introduced into nylon bags $(9 \times 14 \mathrm{~cm}$, pore size of $50 \mu \mathrm{m}$ : PA 50/27 WHPW, Saati France Co., Sailly Saillisel, France). PAH concentration was previously determined as explained below.

Figure 1 indicates the profile of $n$-alkanes in the main species contained in the mixture of the collected grass samples (40\% Festuca arundinacea, 30\% Dactylis glomerata, 20\% Arrhenatherum elatius and $10 \%$ Lolium perenne) according to the literature.

\subsection{Analytical methods}

PAH extraction in grass was carried out by toluene and analysed by liquid chromatography according to the procedure described by Dugay et al. (2002) and adapted by Tankari Dan-Badjo et al. (2007). PAH calibration curves were performed by diluting a standard mixture (M-610-QC, Interchim) containing the 16 PAHs listed by the United States Environmental Protection Agency. The PAH extraction yield varied from 45 to $100 \%$. The quantification limit was $0.5 \mathrm{ng} / \mathrm{g}$ DM.

$\mathrm{N}$-alkanes were extracted by chloroform and analysed by gas chromatography according to Garcia (2005). A standard sample of $n$-alkanes allowed determining the retention time of the studied compounds. The concentration was calculated with regard to the alkane standard. The limit of detection was established at $1 \mathrm{ng} / \mathrm{g}$ DM.

\subsection{Animals and proceedings}

Three cows fitted with a permanent rumen cannula (\#2C, Bar Diamond Inc. Parma, ID), and fed with a total mixed ration, were used for this trial. The incubation times of the nylon bags in the rumen were $1,3,6,12,24$ and $48 \mathrm{~h}$. For each time of incubation, 6 bags were introduced into the rumen of each animal. At the end of the incubation periods, bags were removed from the rumen and washed 2 times for 5 minutes in cold water, and then dried at $30{ }^{\circ} \mathrm{C}$ for 5 days before being analysed as explained above. In order to determine the immediate disappearance $(0 \mathrm{~h}), 6$ bags were washed 2 times for 
5 minutes in cold water without any previous incubation. After the drying process $\left(30{ }^{\circ} \mathrm{C}\right.$ for 5 days $)$, the bags were weighed. Afterwards, the residues of the 6 bags for each time point and each cow were pooled into a single sample before analysis. In each pooled sample the concentration of PAHs, $n$-alkanes and DM was determined.

\subsection{Calculation and statistical analysis}

The in sacco incubation of the grass in cows allowed the calculation of the disappearance rates of each PAH and cuticular $n$-alkanes (for each time point of the kinetics) as follows:

$$
\mathrm{DR}=\frac{\mathrm{C}_{\mathrm{i}}-\mathrm{C}_{\mathrm{r}}}{\mathrm{C}_{\mathrm{i}}} * 100 .
$$

DR: disappearance rate, $\mathrm{C}_{\mathrm{i}}$ : initial concentration (ng/g DM) and $\mathrm{C}_{\mathrm{r}}$ : residual concentration after incubation (ng/g DM). The disappearance of DM was calculated in the same way.

The DRs for the PAHs and $n$-alkanes were adjusted cow by cow (STAT-ITCF 5.0, 1991, Arvalis Institute, Paris, France) according to the model of Ørskov and McDonald (1970):

$$
\mathrm{DR}=\mathrm{a}+\mathrm{b}\left(1-\mathrm{e}^{-\mathrm{ct}}\right)
$$

The parameter "a" represents the immediate disappearance rate, "b" represents the rate of progressive disappearance, and "c" the disappearance slope. In this way, DRs of each PAH and the main $n$-alkane $\left(\mathrm{C}_{31}\right)$ are modelled based on the average of 3 cows. Then, the asymptotic plateau of the disappearance model was considered to be reached following Costera et al. (2006): $0.95 \times[a+b]$. Contrarily, the disappearance rate of the DM did not follow the classical model and had to be adjusted to a linear model $(\mathrm{DR}=\mathrm{a}+\mathrm{ct})$.

The different DR values were compared by analysis of variance (ANOVA) using the GLM procedure of SAS (version 9.1, 2004, SAS Institute, Cary, NC). The factors included in the model were the studied compounds (Phe, Pyr, BaP, $\mathrm{C}_{31}, \mathrm{DM}$ ), the incubation time $(1,3,6,12,24,48 \mathrm{~h})$ and the interaction between the compound and incubation time. The 3 cows used corresponded to 3 repetitions. The average DR values per compound were compared for a given incubation time using a multiple t-test according to Tukey. The significance was concluded at the threshold of $P<0.05$.

\section{RESULTS AND DISCUSSION}

\subsection{PAH and $n$-alkane concentrations in the grass}

The average concentrations of PAHs $(n=5)$ and $n$-alkanes $(n=4)$ measured in grass after contamination are presented in Table I. They were found to be between 36 and $85 \mu \mathrm{g} / \mathrm{g}$ DM. Although each of the three PAHs was applied on the grass area at a similar amount, it has to be noted that some differences were observed in the final concentrations (Tab. I). This result suggests that the attachment of Phe to the cuticle of the grass is weaker than that of Pyr and $\mathrm{BaP}$ as a consequence of the
Table I. Concentration of PAHs and $n$-alkanes ( $\mu \mathrm{g} / \mathrm{g}$ DM) in contaminated grass.

\begin{tabular}{cccccc}
\hline & PAH & \multicolumn{3}{c}{$n$-alkane } \\
\hline Phe & Pyr & BaP & $\mathrm{C}_{29}$ & $\mathrm{C}_{31}$ & $\mathrm{C}_{33}$ \\
$36.2 \pm 8.5$ & $84.7 \pm 39$ & $57.8 \pm 35$ & $19.3 \pm 0.1$ & $31.0 \pm 1$ & $7.6 \pm 0.3$ \\
\hline
\end{tabular}

DM: dry matter, PAH: polycyclic aromatic hydrocarbons, Phe: phenanthrene, Pyr: pyrene, BaP: benzo[a]pyrene.

differences in lipophilicity between these compounds. Nevertheless, lipophilicity does not explain the differences between Pyr and BaP. In any case, each of the three PAHs was found at a sufficient level to ensure the quality of the experimental design. Regarding the $n$-alkanes, concentrations were found to be between 7 and $19 \mu \mathrm{g} / \mathrm{g} \mathrm{DM}$ and the highest concentrations were found for $\mathrm{C}_{31}$, as observed by several authors (Mayes et al., 1986; Maffei, 1996; Cortes et al., 2005).

\subsection{In sacco disappearance of PAHs, $n$-alkanes and DM}

The kinetics of in sacco disappearance of the studied PAHs are presented in Figure 2. The differences shown, as notable variations in DR between time points observed, need to be interpreted with caution, especially those of the very lipophilic compounds Pyr and BaP. It can be noted that the DR was rapidly very high for all three $\mathrm{PAH}$ compounds. Indeed, concentration of the 3 PAHs disappeared beyond $70 \%$ in the first hour of incubation to reach a DR of over $80 \%$ at $48 \mathrm{~h}$. The immediate disappearance was higher for Phe than that for the two other PAHs. Moreover, $\mathrm{DR}_{\mathrm{Phe}}$ was significantly higher during the first three hours of incubation than $\mathrm{DR}_{\mathrm{Pyr}}$ and $\mathrm{DR}_{\mathrm{BaP}}$. Thus, the less hydrophobic compound Phe disappeared more rapidly in the ruminal liquid than the more lipophilic ones (Pyr and $\mathrm{BaP})$.

The in sacco disappearance of the studied $n$-alkanes is presented in Figure 3. No significant differences were found between compounds for each kinetic time point $(P>0.05)$. Therefore, the most abundant compound, $\mathrm{C}_{31}$, can be used in further modelling as a representative $n$-alkane. Nevertheless, all $n$-alkanes disappeared significantly more slowly than PAHs. Indeed, the DR of all $n$-alkanes was close to $30 \%$ during the first hour of incubation, and none of the compounds reached a disappearance rate of $70 \%$ even at $48 \mathrm{~h}$.

Finally, DM disappearance also increased with time (Fig. 4) but the exponential model did not correspond to the measured time points of $\mathrm{DR}_{\mathrm{DM}}$. Therefore, a linear model has to be used for fitting. Thus, only $20 \%$ of DM disappeared during the first hour, $30 \%$ after $12 \mathrm{~h}$, about $50 \%$ after $24 \mathrm{~h}$ and $70 \%$ at the end of the kinetics.

Among the studied compounds, the most rapid disappearance in the rumen was observed for PAHs, especially Phe, followed by $n$-alkanes and lastly, DM. These data suggest that PAHs were adsorbed on the surface of the cuticle and liberated at the beginning of the cuticle hydrolysis, which was found to be progressive with time. Thus, PAHs would disappear from 
Disappearance Rate $(\%)$

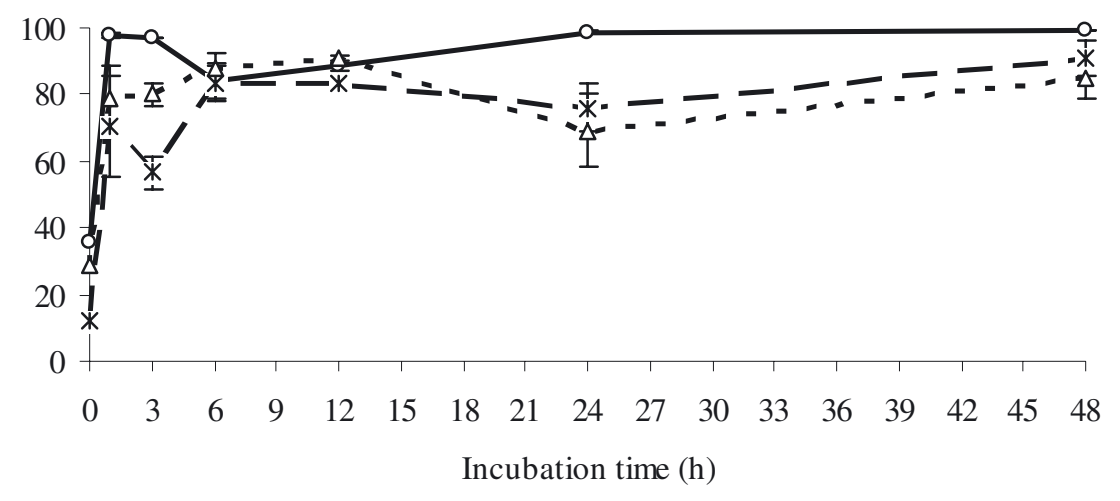

$\longrightarrow$ - Phe $-*-$ Pyr $--\Delta--\mathrm{BaP}$

Figure 2. In sacco disappearance kinetics of grass-bound PAHs. PAH: polycyclic aromatic hydrocarbons, Phe: phenanthrene, Pyr: pyrene, BaP: benzo[a]pyrene.

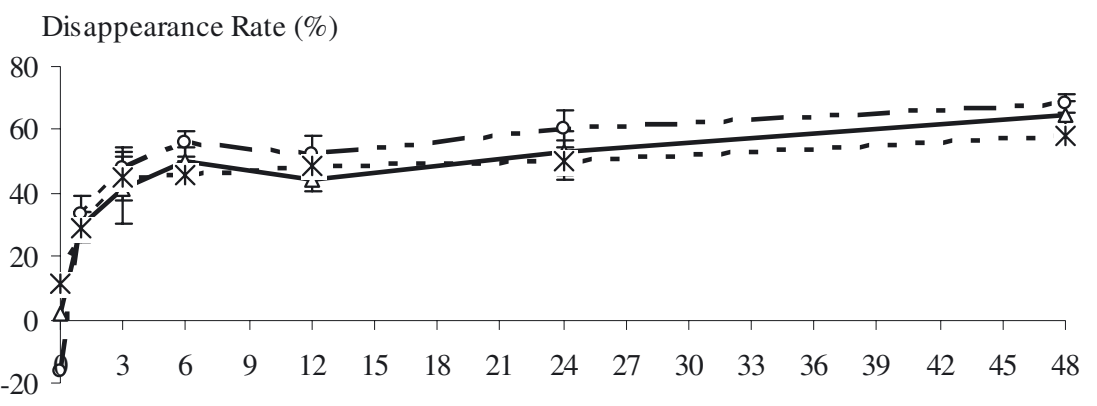

Incubation time (h)



Figure 3. In sacco disappearance kinetics of grass $n$-alkanes.

Dis appearance Rate $(\%)$

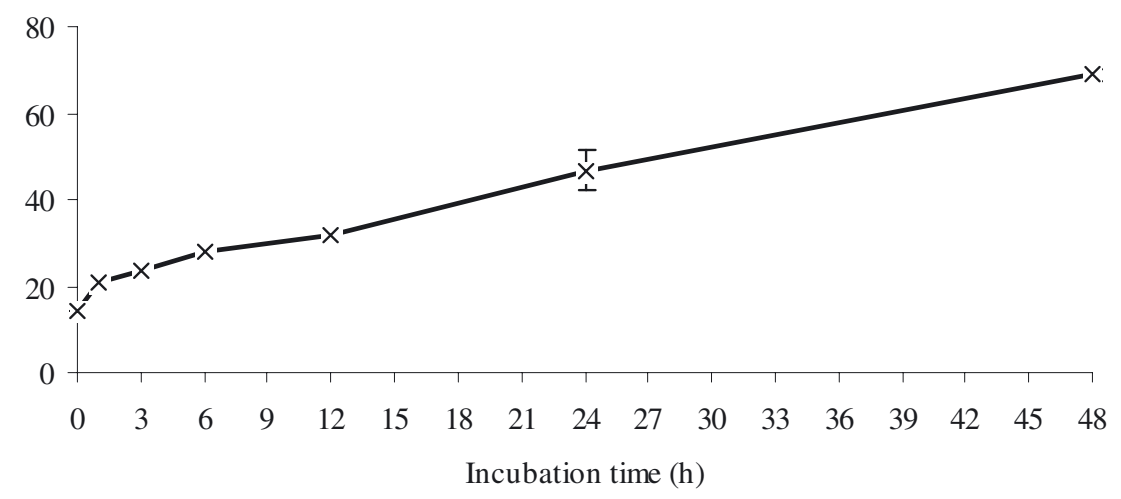

Figure 4. In sacco disappearance kinetics of grass DM. DM: dry matter. 
Table II. Effect of compound and incubation time on disappearance rates (\%) in sacco.

\begin{tabular}{|c|c|c|c|c|c|c|c|}
\hline Effect & $P$-value & Incubation time (h) & $\mathrm{BaP}$ & Pyr & Phe & $\mathrm{C}_{31}$ & DM \\
\hline Compound (Cp) & $<0.001$ & 1 & $78.6^{\mathrm{b}}$ & $70.4^{\mathrm{b}}$ & $97.9^{\mathrm{a}}$ & $33.1^{\mathrm{c}}$ & $21.0^{\mathrm{c}}$ \\
\hline Incubation time (It) & $<0.001$ & 3 & $80.0^{\mathrm{a}}$ & $56.6^{\mathrm{b}}$ & $97.2^{\mathrm{a}}$ & $48.1^{\mathrm{b}}$ & $23.8^{\mathrm{c}}$ \\
\hline Interaction $\mathrm{Cp} \times$ It & $<0.001$ & 6 & $87.8^{\mathrm{a}}$ & $83.3^{\mathrm{a}}$ & $84.3^{\mathrm{a}}$ & $55.6^{\mathrm{b}}$ & $28.2^{\mathrm{c}}$ \\
\hline \multirow[t]{2}{*}{ Cow } & NS & 12 & $90.7^{\mathrm{a}}$ & $83.2^{\mathrm{a}}$ & $88.3^{\mathrm{a}}$ & $52.2^{\mathrm{b}}$ & $31.8^{\mathrm{c}}$ \\
\hline & & 24 & $69.2^{\mathrm{b}}$ & $76.1^{\mathrm{b}}$ & $98.8^{\mathrm{a}}$ & $60.3^{b c}$ & $46.7^{\mathrm{c}}$ \\
\hline Root MSE & 5.48 & 48 & $84.6^{\mathrm{ab}}$ & $90.9^{\mathrm{a}}$ & $99.2^{\mathrm{a}}$ & $68.2^{\mathrm{b}}$ & $68.9^{b}$ \\
\hline
\end{tabular}

a, b, c: Means with different letters within the same line indicate a difference at the threshold of $P<0,05$. DM: dry matter, Phe: phenanthrene, Pyr: pyrene, BaP: benzo[a]pyrene.

Table III. Parameters of the in sacco disappearance models for the three PAHs, $\mathrm{C}_{31}$ and DM.

\begin{tabular}{llllll}
\hline Variable & model & $\mathrm{a}$ & $\mathrm{b}$ & $\mathrm{c}$ & $\mathrm{R}^{2}$ \\
\hline Phe & $\mathrm{DR}_{\mathrm{Phe}}=\mathrm{a}+\mathrm{b}\left(1-\mathrm{e}^{\mathrm{ct}}\right)$ & -85 & 179 & 11,2 & 0,99 \\
$\mathrm{Pyr}$ & $\mathrm{DR}_{\mathrm{Pyr}}=\mathrm{a}+\mathrm{b}\left(1-\mathrm{e}^{\mathrm{ct}}\right)$ & -33 & 116 & 5,9 & 0,99 \\
$\mathrm{BaP}$ & $\mathrm{DR}_{\mathrm{BaP}}=\mathrm{a}+\mathrm{b}\left(1-\mathrm{e}^{\mathrm{ct}}\right)$ & -32 & 112 & 4,1 & 0,97 \\
$\mathrm{C}_{31}$ & $\mathrm{DR}_{\mathrm{C} 31}=\mathrm{a}+\mathrm{b}\left(1-\mathrm{e}^{\mathrm{ct}}\right)$ & -25 & 83 & 1,1 & 0,98 \\
$\mathrm{DM}$ & $\mathrm{DR}_{\mathrm{DM}}=\mathrm{a}+\mathrm{ct}$ & 19,3 & & 1,1 & 0,98 \\
\hline
\end{tabular}

DM: dry matter, PAH: polycyclic aromatic hydrocarbons, Phe: phenanthrene, Pyr: pyrene, BaP: benzo[a]pyrene, DR: disappearance rate.

the grass samples as soon as epicuticular $n$-alkanes begin to be degraded (Boudon et al., 2002). Differential disappearances between PAHs could be linked to their chemical properties, as suggested by Bakker et al. (2001). Indeed, these authors found that PAHs with low molecular weight were predominantly present in cuticular waxes and inside the leaves, whereas PAHs with high molecular weight remained only on the surface of the leaves. Indeed, Phe had a lower molecular weight and was less lipophilic than Pyr and BaP, but its disappearance in comparison with the heavier Pyr and BaP did not confirm the observations of Bakker et al. (2001). Jurjanz and Rychen (2007) reported a higher extraction in vitro of Phe in aqueous media than for Pyr and BaP. Therefore, Phe would be easily desorbed in an aqueous medium such as the rumen from the waxy surface of leaves. Wang et al. (2008) observed, on annual leaves, that the concentration of PAHs in cuticular wax was one- to two-fold higher than in the inner tissues. Finally, the question can be asked if a longer exposition of grass would allow PAHs to enter the inner leaf tissues and then change their ruminal disappearance dynamics.

To our knowledge, no data are available in the literature to discuss the disappearance of $n$-alkanes in the rumen.

\subsection{Comparison of the disappearance of PAHs, $\mathrm{C}_{31}$ and DM}

The statistical comparison of the effect of compound and incubation time (Tab. II) on the different DR values confirmed observations previously made about the figures.

Although there were notable variations for some time points (for the very lipophilic Pyr and BaP), all three PAHs disappeared very rapidly from incubated grass. The DR of Phe was significantly highest for all studied incubation times. The $\mathrm{DR}_{\mathrm{C} 31}$ was significantly less rapid than PAHs but generally more rapidly than grass DM (Tab. II). Therefore, it seems more pertinent to focus on the generally very rapid disappearance of PAHs in the aqueous medium of the rumen.

The comparison of DR values can be improved when modelled as an exponential function, which is usually done for nutritional purposes. Thus, the modelled disappearance kinetics of PAHs, $\mathrm{C}_{31}$ and DM are compared in Figure 5 and the different model parameters are given in table III. Over the studied period, $\mathrm{DR}_{\mathrm{PAHs}}$ was higher than $\mathrm{DR}_{\mathrm{C} 31}$ and $\mathrm{DR}_{\mathrm{C} 31}$ also appeared to be higher than $\mathrm{DR}_{\mathrm{DM}}$. Within the three studied PAHs, the DR $\mathrm{Dh}_{\mathrm{Ph}}$ was significantly higher than the DR of the two other PAHs $(P<0.001)$. In fact, $\mathrm{DR}_{\mathrm{Phe}}$ reached $91 \%$, while $\mathrm{DR}_{\mathrm{BaP}}$ and the $\mathrm{DR}_{\mathrm{Pyr}}$ reached $80 \%$ and $77 \%$, respectively. The DR values, calculated at the plateau, were not significantly different for Pyr and $\mathrm{BaP}(P>0.05)$. Maximum DR (i.e. $0.95 \times[a+b])$ was reached after an incubation of 21 minutes for Phe, 36 minutes for $\mathrm{BaP}$ and 51 minutes for Pyr. In contrast, the maximum DR for $\mathrm{C}_{31}$ was reached only after 183 minutes of incubation. The linear evolution of the $\mathrm{DR}_{\mathrm{DM}}$ did not allow determining a plateau as for the other compounds, but this linear model (Tab. III) calculated full disappearance of DM after 73 hours of incubation.

The adjustment of the $\mathrm{DR}_{\mathrm{C} 31}$ and $\mathrm{DR}_{\mathrm{PAHs}}$ to the model of Ørskov and McDonald (1970) highlights the similar dynamics between the disappearance of $n$-alkanes and PAHs, even if the $\mathrm{DR}_{\mathrm{C} 31}$ were significantly lower (Fig. 5). The negative values of the immediate disappearance (a) were surprising and should be considered as an artefact due to analytical variations in these lipophilic compounds in the aqueous medium of the rumen. After the start of incubation, the progressively degradable fraction (b) was higher for PAHs, especially for Phe, than for $n$-alkanes (Tab. III). The same hierarchical order is noted for the slopes of the fitted models (c), i.e. the speed of disappearance curves: $\mathrm{Phe}>(\mathrm{Pyr} \& \mathrm{BaP})>\mathrm{C}_{31}$. This leads us to formulate the assumption that $\mathrm{DR}_{\mathrm{C} 31}$ corresponds to the degradation of the epicuticular wax, more easily degradable than the intracuticular wax by the rumen juice. The general representation of the cuticular components proposed by Kunst and Samuels (2003) seems to explain the dynamics of DR kinetics found in this study well. Indeed, PAHs disappear as soon as the epicuticular $n$-alkanes, as their lipophilic support, start to be degraded, and thereafter $n$-alkanes get degraded more 
Disappearance Rate (\%)



Figure 5. Modelled in sacco disappearances of Phe, Pyr, BaP, $\mathrm{C}_{31}$ and DM during the 4 first hours of incubation. DM: dry matter, PAH: polycyclic aromatic hydrocarbons, Phe: phenanthrene, Pyr: pyrene, BaP: benzo(a)pyrene.

quickly than the DM. Furthermore, previously published studies have indicated that ruminal digestion of grass leaves takes place progressively. For example, Dinsdale et al. (1978) found that a thick wall $(0.9 \mu \mathrm{m})$ had been attacked during a 6-h period of digestion. Later, Cheng et al. (1980) carried out a study about the sequence of events in the digestion of fresh legume leaves by rumen bacteria. Their results showed that $8 \mathrm{~h}$ of incubation were necessary to detect a high amount of bacteria in the intercellular spaces of the parenchyma tissue. These data support the evidence of a slower disappearance of DM compared with the disappearance of $n$-alkanes and PAHs. Thus, the different disappearance speeds between PAHs, $n$-alkanes and the DM indicate that PAHs were meanly adsorbed on the surface of leaves. Secondly, their hydrophobicity can explain the slight differences in speed of disappearance noted between the three PAHs.

It is shown here that PAHs are quickly removed from contaminated grass samples, which is the first step of their bioavailability. The in sacco technique did not allow one to conclude if removed PAHs are adsorbed on the cell walls of microorganisms, or if less lipophilic compounds such as Phe are susceptible to passing into the liquid phase of the ruminal content, or if both pathways are used. However, no significant retention effects caused by the grass matrix were shown, and therefore no limitation of the bioavailability of grass-bound PAHs can be expected. Thus, the extraction patterns of these pollutants showed their high bioaccessibility but further work would be needed to elucidate in which digestive compartment they would be absorbed.

The extrapolation of $\mathrm{DR}_{\mathrm{PAHs}}$ in the present work to other hydrophobic pollutants such as dioxins, furans and polychlorobiphenyls can be suggested. Indeed, Costera et al. (2006) observed a very high transfer of polychlorodibe nzop-dioxins (PCDDs), polychlorodibe nzofurans (PCDFs) and polychlorobiphenyls (PCBs) from contaminated hay to milk. It would now be of great interest to confirm our observations by conducting similar studies with roughages, which should be contaminated by a longer period of exposition.

\section{CONCLUSIONS}

This work aimed to determine, by the in sacco procedure, the dynamics of ruminal disappearance of PAHs, cuticular $n$-alkanes and finally, of DM of contaminated grass. The very rapid disappearance of PAHs from contaminated grass allows one to conclude that these pollutants are very rapidly released from the surfaces of leaves. The disappearance behaviour of 
cuticular $n$-alkanes in the rumen had similar disappearance kinetics, but to a lesser extent than PAHs. Both compounds disappeared from grass more rapidly than the grass DM. This result confirms the adsorption of the PAHs on the surface of the leaves and probably on the cuticular $n$-alkanes. This experiment gives new insight into the way that PAHs are adsorbed on grass and how these compounds are released in the rumen to become bioaccessible for ruminants. Therefore, if PAHs become bioaccessible for ruminants, their transfer to milk could be a consequence. Further studies should elucidate if the commonly reported high degree of PAH metabolisation should be linked to the high microbial activity in the rumen.

\section{REFERENCES}

Bakker M.I., Koerselman J.W., Tolls J., Kolloffel C. (2001) Localization of deposited polycyclic aromatic hydrocarbons in leaves of plantago, Environ. Toxicol. Chem. 20, 1112-1116.

Boudon A., Peyraud J.L., Faverdin P. (2002) The release of cell contents of fresh rye-grass (Lolium perenne L.) during digestion in dairy cows: effect of the intracellular constituents, season and stage of maturity, Anim. Feed Sci. Technol. 97, 83-102.

Cheng K.J., Fay J.P., Howarth R.E., Costerton J.W. (1980) Sequence of events in the digestion of fresh legume leaves by rumen bacteria, Appl. Environ. Microbiol. 40, 613-625.

Cortes C., Damasceno J.C., Bechet G., Prache S. (2005) Species composition of ryegrass (Lolium perenne) and tall fescue (Festuca arundinacea) mixtures using various combinations of $n$-alkanes, Grass Forage Sci. 60, 254-261.

Costera A., Feidt C., Marchand P., Le Bizec B., Rychen G. (2006) $\mathrm{PCDD} / \mathrm{F}$ and $\mathrm{PCB}$ transfer to milk in goats exposed to a long-term intake of contaminated hay, Chemosphere 64, 650-657.

Dinsdale D., Jane Morris E., Bacon J.S.D. (1978) Electron microscopy of the microbial populations present and their modes of attack on various cellulosic substrates undergoing digestion in the sheep rumen, Appl. Environ. Microbiol. 36, 160-168.

Dove H., Mayes R.W. (1991) The use of plant wax alkanes as marker substances in studies of the nutrition of herbivores: a review, Aust. J. Agric. Res. 42, 913-952.

Dugay A., Herrenknecht C., Czok M., Guyon F., Pages N. (2002) New procedure for selective extraction of polycyclic aromatic hydrocarbons in plants for gas chromatographic-mass spectrometric analysis, J. Chrom. A. 958, 1-7.

Ferreira L.M.M., Garcia U., Rodrigues M.A.M., Celaya R., Dias-da-Silva A., Osoro K. (2007) The application of the $n$-alkane technique for estimating the composition of diets consumed by equines and cattle feeding on upland vegetation communities, Anim. Feed Sci. Technol. 138, 47-60.

Garcia C. (2005) La 3-hydroxyacyl-CoA déshydratase de l'acyl-CoA élongase: identification et caractérisation de gènes candidats chez Arabidopsis thaliana, $\mathrm{PhD}$ Thesis, Victor Segalen Bordeaux 2 University.
Grova N., Feidt C., Laurent C., Rychen G. (2002) [14C] Milk, urine and faeces excretion kinetics in lactating goats after an oral administration of [14C]polycyclic aromatic hydrocarbons, Int. Dairy J. 12, 1025-1031.

Grova N., Laurent C., Feidt C., Rychen G., Laurent F., Lichtfouse E. (2000) Gas chromatography-mass spectrometry study of polycyclic aromatic hydrocarbons in grass and milk from urban and rural farms, Eur. J. Mass Spectr. 6, 457-460.

Grova N., Monteau F., Le Bizec B., Feidt C., André F., Rychen G. (2005) Determination of Phenanthrene and Hydroxyphenanthrenes in Various Biological Matrices at Trace Levels using Gas Chromatography-Mass Spectrometry, J. Anal. Toxicol. 29, $175-181$.

Jurjanz S., Rychen G. (2007) In vitro bioaccessibility of soil-bound polycyclic aromatic hydrocarbons in successive digestive compartments in cows, J. Agric. Food Chem. 55, 8800-8805.

Kunst L., Samuels A.L. (2003) Biosynthesis and secretion of plant cuticular wax, Prog. Lipid Res. 42, 51-80.

Maffei M. (1996) Chemotaxonomic significance of leaf wax alkanes in the Graminae, Biochem. Syst. Ecol. 24, 53-64.

Mayes R.W., Lamb C.S., Colgrove P.M. (1986) The use of dosed and herbage $n$-alkanes as markers for the determination of herbage intake, J. Agric. Sci. 107, 161-170.

Michalet-Doreau B., Verité R., Chapoutot P. (1987) Méthodologie de mesure de la dégradabilité in sacco de l'azote des aliments dans le rumen, Bull. Tech. CRZV Theix INRA 69, 5-7.

Ounnas F., Jurjanz S., Dziurla A., Guiavarc'h Y., Feidt C., Rychen G. (2009) Relative bioavailability of soil-bound Polycyclic Aromatic Hydrocarbons in goats, Chemosphere 67, 115-122.

Ørskov E.R., McDonald P. (1970) The estimation of protein degradability in the rumen from incubation measurements weighted according to rate of passage, J. Agric. Sci. Cambridge 92, 499-503.

Simonich S.L., Hites R.A. (1994) Vegetation-atmosphere partitioning of polycyclic aromatic hydrocarbons, Environ. Sci. Technol. 28, 939943.

Tankari Dan-Badjo A., Ducoulombier-Crépineau C., Soligot C., Feidt C., Rychen G. (2007) Deposition of platinum group elements and polycyclic aromatic hydrocarbons on ryegrass exposed to vehicular traffic, Agron. Sustain. Dev. 27, 261-266.

Thomas G.O., Smith K.E.C., Sweetman A.J., Jones K.C. (1998) Further studies of the air-pasture transfer of polychlorinated biphenyls, Environ. Pollut. 102, 119-128.

Van Soest P.J. (1982) Nutritional ecology of the ruminant, O\&B Books, Corvallis, Oregon.

Wang Y.Q., Tao S., Jiao X.C., Coveney R.M., Wu S.P., Xing B.S. (2008) Polycyclic aromatic hydrocarbons in leaf cuticles and inner tissues of six species of trees in urban Beijing, Environ. Pollut. 151, 158164.

West C.E., Horton B.J. (1976) Transfer of polycyclic aromatic hydrocarbons from diet to milking rats, rabbits and sheep, Life Sci. 19, 543-551. 